\title{
Joint laxity in the performing arts
}

\author{
H Bird, MA, MD, FRCP \\ Emeritus Professor of Pharmacological Rheumatology, University of Leeds; Retired Honorary Consultant Rheumatologist, General Infirmary at \\ Leeds; and Visiting Professor in Performing Arts Medicine, University College, London, United Kingdom
}

Corresponding author: H Bird (howard.a.bird@gmail.com)

Traditional scoring systems for the assessment of joint flexibility are reviewed and reasons for variation in joint laxity are defined. The value of controlled joint laxity in the hands and arms of musicians is then discussed as well as the desirability of adjusting laxity at the various joints used in the different styles of dance, some of them ethnic, that depend on the specific articular characteristics of each different dancer.

S Afr Med J 2016;106(6 Suppl 1):S42-S44. DOI:10.7196/SAMJ.2016.v106i6.10990

The author wishes to acknowledge the immense contribution of Peter Beighton to his thinking over many years. When he was a new clinical medical student at St Thomas's Hospital, London, Peter was the medical registrar on the same firm. This instilled a life-long interest in inheritable disorders of connective tissue which, at the time of the author's retirement, accounted for some $80 \%$ of his clinical practice.

Subsequently, the author joined Peter and Rodney Grahame as the junior editor of Hypermobility of Joints, a monograph published by Springer that has now seen four editions since the first was published in 1983.

This review article is partly based upon the chapter on the advantages and disadvantages of joint flexibility in the performing arts, to which this author has contributed in each successive edition.

\section{Measurement of the range of joint movement}

Individuals with hyperflexible joints (double-jointedness) have fascinated over many centuries, some using this anatomical attribute in pursuit of a career, while others suffer joint symptoms because of them.

In attempting to quantify this, the international yardstick for measurement has long been the scoring system suggested by Beighton in $1973^{[1]}$ though it is sometimes forgotten that this was adapted from an earlier 1964 scoring system that was slightly more complex. ${ }^{[2]}$ Beighton's need was for a quick, simple score for epidemiological purposes that could be performed in seconds in the field or even used for self-assessment by postal questionnaire. It is still widely used in patient information leaflets and serves to alert general practitioners to the possibility of joint hypermobility. It awards one point for each of nine simple manoeuvres. It has been incorporated in other assessments such as the Brighton Criteria for joint hypermobility syndrome,${ }^{[3]}$ formulated by consensus, which were designed for the assessment of patients attending clinic because of painful, lax joints and which are considered by some to be perhaps too intrusive for epidemiological research.

The Beighton score does not attempt to inform on pathogenesis, given that determinants of the range of movement observed are varied, include the inherited characteristics of the collagen of the soft tissues, the shape of the bony and cartilaginous articulating surfaces, the acquired muscle tone restricting movement, and neurological factors such as impairment of the reflex arc and of proprioception. ${ }^{[4]}$ More precise methods of accurately recording the range of movement at a single joint with a preset torque are available, such as the Leeds hyperextensometer ${ }^{[5]}$ that was used to demonstrate the enhanced laxity of the peripheral ligaments during pregnancy for the first time. The Leeds proprioceptometer is also of value in this context. ${ }^{[6]}$

In the performing arts, the effect of regular training on the Beighton score, either by stretching or by strengthening to stabilise, may be considerable, and there is often wide variation in scores before and after 'warm-up', indicating the need for precision in the circumstances in which the joints are tested.

Beighton has suggested that rapid advances in our understanding of molecular genetics may facilitate elucidation of the pathogenesis of the various hypermobility syndromes within a decade (personal communication, P Beighton 2015).

\section{Variation in range of joint movement within the individual and ethnic variation}

Joint laxity is not always uniform throughout a single individual, probably further attesting to the various contributory factors. Extreme laxity mainly restricted to the hips with lesser laxity elsewhere is very typical of the acetabular dysplasia group and a careful search often reveals minor orthopaedic abnormalities elsewhere and sometimes a mild scoliosis. Often this laxity is also seen at the shoulders, but here the inherited collagen structure may play more of a part. By contrast, where hyperlaxity is more uniform throughout the body, collagen structure is likely to be a main determinant, especially if there are also fragile skin, varicose veins and herniae. Difficulties with balance and spatial awareness may hint at a neurological influence in laxity and a large difference between flexibility before and after warm-up, or the need for a long warm-up to enhance flexibility, hints at acquired laxity achieved through neuromuscular control.

There are also observed differences in joint laxity with age, gender and hormones. Studies from Edinburgh ${ }^{[7]}$ and London ${ }^{[8]}$ confirm work by Beighton ${ }^{[1]}$ that joint laxity is most pronounced in children, then with a diminution throughout adult life. Growth spurts and the onset on menstruation in females may cause changes in this gradient during adolescence and either can cause joint symptoms for the first time. The greater laxity of female joints compared with comparable joints in age-matched males may in part be hormonal but can also result from different features of the female skeleton. It is usually accepted that the dominant arm displays some $5 \%$ less laxity than the nondominant arm.

Ever since Socrates described the Scythians as a race of horse people whose elbow joints were too lax to allow them the use of bows and arrows in war, an ethnic variation in joint laxity has been accepted. Data are not always robust, one of the most seminal of 
studies being that of the laxity of the finger joints in the different ethnic groups across South Africa. ${ }^{[9]}$ Those of Indian extraction had the most flexible fingers and the Europeans the least, with the native Africans in between. Similar findings were found in the UK. ${ }^{[10]}$ Across Europe there is a suspicion of a gradient of joint laxity from north to south, Nordic races usually less lax than Mediterranean races.

World-wide there are probably pockets of excessive joint laxity, one being the Middle East. Iraqi medical students showed significantly greater joint laxity than age-matched medical students in the UK. ${ }^{[1]}$ However, sometimes acquired factors may contribute to observed joint laxity, as in the common squatting position seen in the Far East. In Thailand, the characteristic hyperextension of the fingers in dance is said to be achieved by training from childhood. It is not clear whether the pre-eminence of Mongolian females in the circus art of contortion reflects a genetic anatomical aptitude or the fact that contortion is widely taught there, almost as a national sport.

Analysis of joint laxity, its modification where possible and when this is needed and its maintenance is indeed a complicated area but a well-established one in sports science. When it comes to the anatomical and physiological matching of each body to the musical instrument to which it is most suited, this science becomes sketchy even though musicians are largely athletes, mainly of upper limb. ${ }^{[12]}$ The science becomes even more complex in dancers, particularly those from diverse ethnic groups dancing in many different styles.

\section{Joint laxity in musicians}

Unlike shoes or clothes, musical instruments come in a single standard size even though the shape and size of the performers' bodies can vary considerably. It follows that there may need to be adaption of posture, for many hours on end in the case of a professional orchestral player, often leading to musculoskeletal symptoms of strain or overuse syndromes. Adaptations to playing may include the modification of flexibility, either to enhance or to reduce to give stability, which falls within the scope of this review.

Once data from performing arts medicine clinics ${ }^{[13]}$ are corrected for the frequency with which the various instruments are encountered, certain problem instruments emerge. In general fewer problems occur with keyboards or with brass instruments, where the main problems are with embouchure and the soft-tissue flexibility of the lips and facial muscles where considerable strength is also required.

Among woodwind, the oboe and clarinet are held in a physiological position so are less problematic and the player's position can be adapted for the small piccolo and the large bassoon. The problem instrument tends to be the flute, whose length creates an awkward triangle to which the arms have to adapt. Flexibility is an advantage in maintaining this position providing it does not affect the fingers though here specific appliances are available. ${ }^{[14]}$

Among the small string instruments, flexibility of the fingers in the left hand and of the right shoulder can be advantageous. Players can adapt to the double bass, where strength may be more desirable than flexibility. The problem instruments are the cello and classical guitar. With the cello, which requires a slight corkscrew twist of the spine, the pelvis is anchored. So a spine that twists naturally in the opposite direction tends to create overuse. ${ }^{[15]}$ With the classical guitar the lateral stretch required of the inner fingers of the right hand is considerable and can lead to injury. ${ }^{[16]}$

Musical notation also provides hard data that can be of scientific use. If, for example, we consider composer/pianists who largely earned a living by playing the works they composed, the music they wrote surely provides insight into the capabilities of their own fingers.
Thus the piano works of Mozart virtually never contain consecutive thirds whereas these are common in the slightly later works of his near-contemporary composer Czerny. Although this could just be stylistic it is tempting to assume that Czerny but not Mozart might have possessed the lateral flexibility of the middle digits required to facilitate this.

Sergei Rachmaninoff is invariably quoted as a composer/pianist who had very large and flexible hands. This is certainly true as judged from the accounts of those of his pupils who are still alive. However, an almost unique feature of his piano writing is also the requirement of extreme lateral flexibility of the middle three digits when the thumb and little finger are stretched at an interval as wide as a tenth, sustaining the melody. ${ }^{[17]}$

\section{Joint laxity in dancers}

Dance is perhaps more athletic than many sports and has also influenced 'tariff sports' such as gymnastics and diving, where an artistic element contributes towards the mark awarded. ${ }^{[18]}$ There has long been controversy on whether hypermobile joints are an asset or a liability in dance. ${ }^{[19]}$ This author has argued elsewhere that it can invariably be turned into an asset provided it is correctly managed. ${ }^{[20]}$ The more severe syndromes with collagen laxity, such as the serious variants of Ehlers-Danlos syndrome, are rarely found in dancers, probably because such individuals are screened out at audition, though quite severe variants of scoliosis are still compatible with dance. ${ }^{[15]}$

As with instrumentalists, conventional scoring systems are inadequate in this specialised area. A full assessment should consider the degree of laxity of each joint as well as determining equality of leg length, shoulder height and turn-out to inform on biomechanical aspects of the spine. Ideally assessment should be made cold, then warm and sometimes even on fatigue to determine the extent to which the laxity is acquired or inherited and the extent to which the dancer might be susceptible to injury through their laxity. Some features of the Beighton score such as the hyperextended elbow and the sway-back knee are alien to dance, especially ballet, and may already have been corrected by the teachers. Dancers are also adept at recognising and correcting features of hyperlaxity themselves, which sometimes only become apparent when the dancer thinks they are unobserved.

There is considerable diversity between the requirement of the various dance genres, and dancers in an oversubscribed profession are likely to offer many different styles as the best means of securing employment. The average clinician, even if able to visualise musical instruments and the mechanical demands each might make, is unlikely to have a working knowledge of the many types of dance, even in the Western world. In contemporary dance, for example, the demands of the three main styles, Grahame, Cunningham and Release, vary widely. In ethnic populations there is even more diversity as well as in sports for which dance forms a part, for example Capoeira.

Some types of dance would seem to be mutually exclusive. Hiphop and ballet make quite different strains on the upper torso. Releve in Irish dance is the absolute opposite of second position plié in contemporary dance. ${ }^{[20]}$

Ideally, for the elite dancer, a full assessment of joint laxity would include a family and dance history, a full examination cold and warm and even some non-invasive imaging before advising on the injury risk in each of the many varied dance styles and perhaps the introduction of a cross-training exercise programme designed to protect the joints as far as possible and to maximise the dancer's potential in the likely future career. This might be described as an 'improvement clinic' for the performer. 


\section{Modification of joint laxity}

The logical extension of such an improvement clinic would be the application of sports science techniques, already in use for elite athletes, to performing artists. In the context of laxity, joints at which extra flexibility would be beneficial might be subject to stretching and joints at which greater stability was desirable if not essential for the avoidance of injury, should be stabilised. This is analogous to normal anatomy when the flexibility inherent in a ball-and-socket joint is tempered by an adjacent joint that is more stable.

Methods for stretching joints already exist. ${ }^{[17]}$ Among them are simple stretching, passive stretching, ballistic stretching and variants described as progressive neuromuscular facilitation (PNF). There is little existing literature on the optimum method, but there is an inference that PNF, while the most effective, is also the shortest lasting. The frequency with which stretching might be required has also not been much researched.

A variety of strengthening techniques also exist, ${ }^{[21]}$ usually using weights or effort against resistance to increase muscle mass and therefore joint stability albeit at the expense of increased muscle bulk, which may be an anathema to a dancer and their teacher.

There is also the vexed issue of whether a body that in the medical sense is functioning perfectly with the minimal risk of injury is likely to procure a performance of higher artistic quality, which in turn raises the difficult issue of how artistic quality should be judged.

\section{References}

1. Beighton P, Solomon L, Soskolne CL. Articular mobility in an African population. Ann Rheum Dis 1973;32(5):413-418
2. Carter C, Wilkinson J. Persistent joint laxity and congenital dislocation of the hip. J Bone and Joint Surg Br 1964;46:40-45.

3. Grahame R, Bird HA, Child A. The revised (Brighton 1998) criteria for the diagnosis of benign joint hypermobility syndrome (BJHS). J Rheumatol 2000;27(7):1777-1779.

4. Ferrell WR, Tennant N, Baxendale RH, Kusel M, Sturrock RD. Musculoskeletal reflex function in the joint hypermobility syndrome. Arthritis Rheum 2007;57(7):1329-1333. DOI:10.1002/ art. 22992

5. Jobbins B, Bird HA, Wright V. A joint hyperextensometer for the quantification of joint laxity. Eng in Med 1979;10:85-88.

6. Wycherley AS, Helliwell P, Bird HA. A novel device for the measurement of proprioception in the hand. Rheumatology 2005;44(5):638-641.

7. Wynne-Davies R. Acetabular dysplasia and familial joint laxity: Two etiological factors in congenital Wynne-Davies R. Acetabular dysplasia and familial joint laxity: Two
dislocation of the hip. J Bone and Joint Surg Br 1970;52(4):704-716.

8. Silverman S, Constine L, Harvey W, Grahame R. Survey of joint mobility and in vivo skin elasticity in London schoolchildren. Ann Rheum Dis 1975;34(2):177-180.

9. Schweitzer G. Laxity of metacarpophalangeal joints of fingers and interphalangeal joint of the thumb: A comparative inter-racial study. S Afr Med J 1970;44(9):246-249.

0. Wordsworth P, Ogilivie D, Smith R, Sykes B. Joint mobility with particular reference to racial variation and inherited connective tissue disorders. Br J Rheumatol 1987;26(1):9-12.

11. Al-Rawi ZS, Al-Aszawi AJ, Al-Chalabi T. Joint mobility in university students in Iraq. Br J Rheumatol 1985;24(4):326-331.

12. Bird HA. The performing artist as an elite athlete. Rheumatology 2009;48(12):1469-1470. DOI:10.1093/ rheumatology/kep257

13. James I. Survey of orchestras. In: Tubiana R, Amadio PC, eds. Medical Problems of the Instrumental Musician. London: Martin Dunitz; 2000:195-201.

14. Artigues-Cano I, Bird HA. Hypermobility and proprioception in the finger joints of flautists. J Clin Rheumatol 2014;20(4):203-208. DOI:10.1097/RHU.0000000000000109

15. Bird HA. Scoliosis in musicians and dancers. In: Bird HA. Performing Arts Medicine in Clinical Practice. London: Springer; 2015:113-128.

16. Bird HA, Wright V. Traumatic synovitis in a classical guitarist. Ann Rheum Dis 1981;40(2):162-163.

17. Bird HA. Hypermobility in the performing arts and sport. In: Beighton P, Grahame R, Bird HA, eds. Hypermobility of Joints. 4th ed. London: Springer; 2012:125-149.

18. Foley EC, Bird HA. Extreme or 'tariff' sports: Their injuries and their prevention. Clin Rheumatol 2013;32(4):463-467. DOI:10.1007/s10067-013-2188-4

19. Grahame R, Jenkins JM. Joint hypermobility: Asset or liability? A study of joint mobility in ballet dancers. Ann Rheum Dis 1972;31(2):109-111.

20. Foley EC, Bird HA. Hypermobilty in dance: Asset, not liability. Clin Rheumatol 2013;32(4):455-461. DOI:10.1007/s10067-013-2191-9

21. Franklin E. Strengthening the centre. In: Conditioning for Dance. Illinois: Human Kinetics; 2004:109- 